\title{
From Independence to Conciliationism: An Obituary $^{* \dagger}$
}

\author{
Errol Lord \\ Princeton University \\ Forthcoming in Australasian Journal of Philosophy
}

\section{Conciliationism and Independence}

Suppose you and I disagree about $p$. I think $p$, you think $\neg p$. And suppose that we are epistemic peers about whether $p$. For our purposes there are two conditions for epistemic peerhood. First, we both have the same evidence with respect to $p$. Second, I think that you are just as smart as I am and just as likely as I am to get it right about $p$-like questions, and you think the same about me. ${ }^{1}$ Interesting question: What should we believe in light of the fact that we disagree with each other?

People disagree about how to disagree. I'll be interested in conciliationist views of disagreement. Although there are many different possible conciliationist views, they all agree that in cases of peer disagreement, each party should substantially revise their opinions given the fact that they disagree. ${ }^{2}$ Anti-conciliationists think that, at least sometimes, it's permissible to not substantially change your view in light of peer disagreement.

\footnotetext{
*Thanks to Tom Kelly and participants in Tom Kelly's Fall 2011 seminar at Princeton. Thanks also to audiences at Rutgers University and the Northwestern/Notre Dame Epistemology conference, especially Ernie Sosa, Kurt Sylvan, Lisa Miriacchi, Blake Roeber, Ram Neta, Baron Reed, Sandy Goldberg, Tim Loughlin, Kathryn Pogin, and Preston Greene. Thanks also to an anonymous referee.

${ }^{\dagger}$ Draft of July 23, 2013. This is the author's final draft. Citing is encouraged, but please quote from the published version.

${ }^{1}$ If you want to make the second condition stronger by demanding that it's reasonable for each of us to think this, or by demanding that we both know this etc., then feel free. Nothing will turn on how demanding the second condition is.

${ }^{2}$ I won't say much about how much one should change one's views in light of disagreement. The most talked about conciliationist view, the equal weight view, holds that you should change your credence to the average of your pre-disagreement credence and your peer's pre-disagreement credence. Although this is a natural view for the conciliationist to hold, some conciliationists explicity deny that this is their view
} 
A major focal point in the debate between conciliationists and anti-conciliationists is a principle dubbed Independence: ${ }^{3}$

Independence: In evaluating the epistemic credentials of another's expressed belief that $p$, in order to determine how (or whether) to modify my own belief about $p$, I should do so in a way that doesn't rely on the reasoning behind my initial belief about $p$.

It's very plausible that once you accept Independence, you will be forced to accept conciliationism about peer disagreement. Here's Christensen's explanation of why: ${ }^{4}$

Conciliationism will result from combining this sort of principle with the thought that, to the extent that one's dispute-independent evaluation gives one strong reason to think that the other person is equally likely to have evaluated the evidence correctly, one should (in the case where one is quite confident that $p$, and the other person is equally confident that not- $p$ ) suspend belief (or adopt a credence close to .5) in $p$ (Christensen, 2009, pg. 758-59).

The idea is that in cases of peer disagreement, your dispute independent evidence will decisively support thinking that your peer is just as likely to be right as you are. Given Independence, this dispute independent evidence is all the evidence you'll be able to permissibly consult in deciding how seriously to take your peer's opinion. Thus, you should think that her view is just as likely to be right as your own. If you should think her view is just as likely to be right as yours, then you should suspend judgement. Given this nice derivation of conciliationism from Independence, some have gone so far as claim that the whole debate between conciliationists and anti-conciliationists turns on Independence. ${ }^{5}$

The preceding line of thought delivers a nice result for the conciliationist if Independence can be independently motivated. Conciliationists think that it can. Once again here is Christensen explaining the motivation. ${ }^{6}$

(most notably David Christensen; see Christensen (2011)). For discussion of the equal weight view, see Elga (2007) and Fitelson \& Jehle (2009).

3 This formulation comes from Christensen (2011). Christensen holds that the whole debate turns on Independence. That is, he thinks that which view is correct turns on whether Independence is correct. While this is hyperbolic, it is certainly true that the princple has played a major role in the literature. Many other conciliationists endorse versions of the principle. For some prominent examples, see Elga (2007), Kornblith (2010), and Cohen (2013). For prominitent critical discussions, see Kelly (2008), Kelly (2013), and Sosa (2013).

${ }^{4}$ For other, less engaging, explanations, see (Elga, 2007, pg. 486-88), (Cohen, 2013, pg. 100).

${ }^{5}$ The most prominent defender of this claim is Christensen (see Christensen $(2011,2009)$ ). See also Kelly (2013) and King (2012).

${ }^{6}$ See also Cohen (2013), Lackey (2008), and Christensen (2009). 
The motivation behind the principle is obvious: it's intended to prevent blatantly question-begging dismissals of the evidence provided by the disagreement of others. It attempts to capture what would be wrong with a $p$-believer saying, e. g., "Well, so-and-so disagrees with me about $p$. But since $p$ is true, she's wrong about $p$. So however reliable she may generally be, I needn't take her disagreement about $p$ as any reason at all to question my belief." There is clearly something worrisome about this sort of response to the disagreement of others. Used as a general tactic, it would seem to allow a non-expert to dismiss even the disagreement of large numbers of those he took to be experts in the field (Christensen, 2011, pg. 2).

The motivation for Independence, then, is that it explains what's wrong when you are dogmatic in particular ways. That is, it explains what you are doing wrong when you dismiss those who disagree with you by simply appealing to the view you've already come to. If this were always allowed, then you could dismiss even the opinions of those whom you take to be epistemic superiors. This would clearly be irrational. Since Independence explains what's wrong with this, it has something going for it.

Despite this, I will argue here that if the debate between conciliationists and anti-conciliationists turns on Independence, then the conciliationists are in trouble. For Independence is false. There are clear counterexamples. I will argue for this in $\S 2$. $\S 3$ shows that the debate between conciliationists and anti-conciliationists needn't turn on Independence. There are two principles weaker than Independence that still deliver conciliationism. I will argue first that one of them is false. This leaves the second. The second principle doesn't admit of uncontroversial counterexamples. The catch, though, is that the weaker principle doesn't explain what's wrong with all dogmatic reasoning, and hence has not been independently supported by anything extant conciliationists have said. In $\S 4$ I'll argue that it's very plausible that this second principle is also false. If I'm right that this principle is the weakest principle that still yields conciliationism, then the road from Independence to conciliationism is a dead end. $\$ 5$ will clarify the scope of the conclusion we should draw.

Although this paper focuses on the relationship between Independence and conciliationism, I should note before moving on that Independence has gained wider theoretical significance. Metaethics provides two nice examples. First, a central premise in one of Copp (2007)'s arguments for moral naturalism is an independence principle. ${ }^{7}$ Second, independence principles have recently come to the fore in debates about the veracity of evolutionary debunking arguments, especially in Street (2011) and Vavova (FC). If Independence is false, then many of the arguments in those papers need to be reevaluated.

\footnotetext{
${ }^{7}$ Copp doesn't use the label. See Hanin (2012) for illuminating discussion about the connection between Copp and the epistemological literature on disagreement.
} 


\section{The Death of Independence}

Independence is very general. It holds that anytime you disagree - whether you disagree with a peer or not - you shouldn't use your original reasoning in evaluating how seriously you should take the opinion of the person with whom you disagree. This extreme generality is its downfall. There are counterexamples. Here's one: ${ }^{8}$

\section{Mail Woman}

You have recently moved into a new apartment at 10 Maple St. Someone by the name of Adams used to live in your new apartment. Adams, however, never told the post office that she moved. So you keep getting her mail. You know full well that Adams doesn't live at 10 Maple St., despite the evidence you get from the fact that Adams constantly gets mail at that address. Priscilla is a sorter at the post office. She believes that Adams does live at 10 Maple St. You encounter Priscilla and realize she disagrees with you about whether Adams lives at 10 Maple St.

Suppose you decide to evaluate the epistemic credentials of Priscilla's belief that Adams lives at 10 Maple St. She tells you all of her evidence, which is evidence that you also have. Namely, that Adams gets a lot of mail sent to 10 Maple St. Independence says that, while evaluating Priscilla's belief, you shouldn't rely on the reasoning that led you to initially think that Adams doesn't live at 10 Maple St. Plausibly, the reason why you initially formed the belief that Adams doesn't live at 10 Maple St is that you know that only you and your roommate live there (and your roommate isn't Adams). You know this, inter alia, because of certain perceptual experiences you have of the insides of the house and certain pieces of testimony (e.g., from the landlord when you signed the lease). So when evaluating the epistemic credentials of Priscilla's belief, Independence mandates that you ignore these reasons and the reasoning that led you from those reasons to your belief.

\footnotetext{
${ }^{8}$ This case is inspired by Tom Kelly's True Story case, which can be found in Kelly (2008). Kelly also argues against Independence via counterexample in Kelly (2013). In the end, Kelly backs off of providing counterexamples largely because of the ingenuity of Christensen in rebutting extensional counterexamples. I think this is a mistake for reasons I explain below. Kelly goes on to argue that we needn't accept anything like Independence to explain the cases of dogmatism that Christensen uses to motivate Indepedence. I agree with this, and think that my paper as of a kind of companion piece to his. Similar cases are discussed in Sorensen (1988).

I should also note that others have argued against the move from Indenpdence to conciliationism (see Sosa (2013) and Lackey (2010)). As I see it, the problem with those discussions is that they focus entirely on disagreement cases. I think this obscures the fact that Indepedence is very implausible for other reasons. One way to put the difference between those discussions and mine is that Sosa and Lackey's primary target is the conciliationist, while mine is Independence. By focusing first on Independence, we'll be in a better position to see that the prospects of plausibly deriving conciliationism from some principle like Independence are quite dim.
} 
This is an absurd result. When evaluating Priscilla's belief, it is permissible for you to rely on the reasons that led you to initially form the belief. You should obviously discount Priscilla's belief. The fact that she disagrees with you should not change your mind at all about whether Adams lives at 10 Maple St. And this is precisely because of the reasons that led you to initially believe that Adams doesn't live at 10 Maple St. It is not objectionably dogmatic at all for you to reason as follows, 'Priscilla reasonably believes that Adams lives in my apartment. But I know she's wrong. He doesn't live there; I know this because I know that only my roommate and I live there, and Adams is not my roommate.' Mail Woman, then, is a case where it's permissible to rely on the reasoning that initially led you to hold a belief in evaluating the epistemic credentials of someone with whom you disagree. Thus, Independence is false.

Readers familiar with Christensen (2011) might think this is too quick. After all, in that paper Christensen ingeniously counters many seemingly devastating counterexamples to Independence. So it's natural to think that one of the stories told there could be parlayed into a response to Mail Woman. I don't think this is right. In fact, I think that we can confirm this isn't right without even having to look at the details of Christensen's replies. Let me explain.

Christensen assumes in Christensen (2011) that extant challenges to Independence are all extensional. That is, he assumes that the counterexamples simply aim at showing that if you accept Independence, then you're forced to say that one has to conciliate in cases of disagreement where intuitively one shouldn't. Christensen's strategy is to show that Independence is compatible with stories that deliver the right results. That is to say, Christensen's strategy is to show that even though we can't rely on our initial reasoning when evaluating the credentials of someone else's belief, the intuitively correct verdicts can still be obtained.

An example will help illustrate Christensen's strategy. ${ }^{9}$ Suppose you and a friend eat dinner together and decide to split the check. You both independently do the math to see how much you each owe. You try very hard to get the right answer. Not only do you do it in your head several times, you also use two calculators to check your mental math. Each method yields that half the check plus $20 \%$ tip is $\$ 43$. Given this, you are extremely confident that you each owe $\$ 43$. Your friend also seems to be painstakingly seeking the correct answer. You see him write out some equations more than once and you see him pull out his own two calculators. Lo and behold, when you are both done your friend announces that you each owe $\$ 700$ !

The intuition most have is that in this case you needn't suspend judgement about whether you both owe $\$ 43$, given how much confidence your initial evidence makes rational. You might think that accepting Independence bars you from concluding this because, in the case, it bars you from relying on the reasoning that initially led you to believe that you both

\footnotetext{
${ }^{9}$ This is one of the problem cases Christensen discusses.
} 
owe $\$ 43$.

Christensen does think that you shouldn't rely on the reasoning that led you to confidently judge that you both owe $\$ 43$. But he shows that thinking this is compatible with thinking you shouldn't suspend judgment once you find out about the disagreement. This is because, he argues, you'll have independent evidence for thinking that something must be going wrong with your friend. This is because you know more facts about yourself than you do about your friend. You know, for example, that you haven't recently taken any mind altering drugs, you know that you were actually paying attention, you know that you're not joking, you know you actually rechecked, etc. You don't, however, know that these things are true of your friend. Since you know something out of the ordinary must have happened in order for you to disagree about this and you can eliminate many of the possible explanations of this in your own case but not in the case of your friend, it's reasonable for you to think something weird happened with your friend and thus not take the disagreement particularly seriously. Or so says Christensen.

I'm not interested in whether Christensen's reply works (at least not right now). What I'm interested in is his strategy. He clearly thinks that what he needs to do is to produce some other evidence that allows you to negatively assess the epistemic credentials of the belief of the person with whom you disagree. Certainly this is a necessary condition for replying to these objections if the are merely extensional.

My objection is not extensional at all. It's not that Independence is false because it entails that in Mail Woman one cannot negatively assess the epistemic credentials of Priscilla's belief. I'm sure Independence is compatible with many stories that would allow for such an assessment. I'm objecting to the fact that Independence is incompatible with any explanation of why it's permissible for you to negatively assess the credentials of Priscilla's belief that appeals to the reasons for which you initially came to hold the belief. This is what is objectionable, for it is perfectly fine for you to negatively assess the credentials of Priscilla's belief because of the reasons for which you initially came to hold the belief.

One might respond by pointing out that it is compatible with Independence that the fact that you have more evidence than Priscilla plays an important role in explaining why you can discount Priscilla's belief. After all, the fact that you have more evidence than Priscilla wasn't part of your initial reasoning about whether Adams lives at 10 Maple St. Thus, you still comply with Independence if you discount Priscilla's belief because you have more evidence than she does. ${ }^{10}$

It is true that you can comply with Independence by discounting Priscilla's belief merely because you have more evidence than she does. But you cannot actually cite that evidence and the reasoning from it to your conclusion as a reason to discount Priscilla's belief. This is bizarre. It is completely bizarre to hold that it is permissible for you to cite the fact that you have more evidence than she does but impermissible to actually cite that evidence.

\footnotetext{
${ }^{10}$ Thanks to an anonymous referee for suggesting this reply.
} 
To dramatize the point imagine there is a epistemic referee overseeing your interactions with Priscilla. You are asked to give a justification for why you discount her belief. You begin by noting you have more evidence than Priscilla. The referee looks on in silence. You then start listing all of this evidence you have for thinking Adams doesn't live at 10 Maple St and the reasoning from this evidence to the conclusion that Adams doesn't live at 10 Maple. If Independence is true, the referee will be loudly objecting to this, most likely with a whistle. This combination - silence at the beginning and lots of whistling later - is bizarre. If you can permissibly cite the fact that you have more evidence, you can permissibly cite that evidence. Since you can permissibly cite the fact you have more evidence, you can cite the evidence. Thus, Independence is false.

\section{Hope for the Conciliationist}

As we've seen, it is popular in the debate about disagreement to think that the debate between conciliationists and anti-conciliationists turns on Independence. But Independence is false. Does that mean the anti-conciliationists win? I don't think so. For there are at least two principles weaker than Independence that still lead to conciliationism.

To see this, think of why it is that you can appeal to the reasons that led you to initially believe that Adams doesn't live at 10 Maple without being dogmatic. It's at least partly because you have those reasons and Priscilla doesn't. That is, since your evidential situation is much better than hers, it's permissible for you to cite the reasons you have that she doesn't in explaining why you shouldn't take her opinion seriously.

Given the way we defined what it is for there to be a peer disagreement, peer disagreements will never be like this. This is because part of what it is to disagree with a peer is to disagree with someone that has the same evidence as you. Let's call those with whom we share all of the $p$-related evidence our evidential peers. The preceding thoughts suggest a principle weaker than Independence, namely $S$ (ame)E(vidence) Independence:

SE Independence: In evaluating the epistemic credentials of an evidential peer's expressed belief that $p$, in order to determine how (or whether) to modify my own belief about $p$, I should do so in a way that doesn't rely on the reasoning behind my initial belief about $p$.

If accepting Independence leads one to be a conciliationist, then so will SE Independence. Recall that we got from Independence to conciliationism by appealing to the two conditions that must be met in order for a disagreement to be a peer disagreement. Namely, epistemic peers are both evidential peers and they both take the other parties to be just as likely to be right about $p$-questions as they are. SE Independence just builds the evidential peerhood condition into the principle itself. 
I still think SE Independence is too strong. This is because it overly restricts what epistemic superiors can appeal to in explaining the negative epistemic credentials of the beliefs of those who are epistemically inferior. For example, consider Mid-Term.

\section{Mid-Term}

John, a professional philosopher, just handed backgraded versions of the midterm he gave in his upper-level class on epistemology. John always has an exegetical section on his tests. In this section, students are given passages from papers they have read and asked to reconstruct the arguments contained within the passages. John thinks that the conclusion of the argument contained within a certain passage is $p$. One of his students, Ben, disagrees. He thinks the conclusion is $\neg p$.

Suppose that John believes the conclusion is $p$ simply because of what the passage says. And suppose that Ben is conceptually sophisticated enough to understand what is being said. Now suppose John wants to evaluate the epistemic credentials of Ben's belief about what the answer is. If SE Independence were true, then John wouldn't be allowed to appeal to the reasons why he initially formed the belief that $p$ is the answer. But this seems wrong. It seems perfectly appropriate for John to negatively assess the credentials of Ben's belief because of what the text says. It would be fine for John to point out to Ben the sentence(s) that he takes to conclusively show that the conclusion of the passage is $p .{ }^{11}$

Of course, Mid-Term lacks the other defining characteristic of cases of peer disagreement. Namely, in Mid-Term neither John nor Ben believe that the other is just as likely to be right about $p$-questions. They both believe that John is more reliable about $p$-questions. This opens the door to one more principle - viz. Peer Independence.

Peer Independence: In evaluating the epistemic credentials of an epistemic peer's expressed belief that $p$, in order to determine how (or whether) to modify my own belief about $p$, I should do so in a way that doesn't rely on the reasoning behind my initial belief about $p$.

\footnotetext{
${ }^{11}$ Objection: This is not a case of evidential peerhood. After all, John will have lots more experience with philosophical texts and arguments, and thus will have lots more evidence than Ben. This is why it's okay to negatively assess Ben's belief by appealing to the reasons that led John to think $p$ is the conclusion. Reply: It's true that, in one sesne of evidential peer, John and Ben aren't evidential peers. But if we think it's possible for their to be evidential peers in the sense relevant to the debate about disagreement, then we better not think a difference in experience in this type of case disallows evidential peerhood. We want our view of evidential peerhood to be coarse grained enough to capture the sense in which I can be an evidential peer with another philosopher, even one who has more experience. Moreover, cases like this will be possible as long as you think that epistemic superiors and inferiors can be evidential peers. I don't see why this would be impossible unless we accept a very fine grained view about evidential peerhood.
} 
Again, if Independence leads to conciliationism, then so will Peer Independence. Now we've just moved both special conditions of the epistemic peer case into the principle itself.

Luckily for the conciliationists, Peer Independence doesn't have any uncontroversial counterexamples. Any purported counterexamples will cut to the core of the debate between the conciliationists and anti-conciliationists. Unfortunately, there is an obvious catch with moving from Independence to Peer Independence.

The catch is that Peer Independence doesn't explain what's wrong with all cases of objectionably dogmatic responses to disagreement. In order to show this, it suffices to point out that it's possible to be objectionably dogmatic with non-peers! An extension of MidTerm is such a case. Suppose that Ben responds to John's appeal to the text as follows, 'I understand that John thinks $p$ because of those claims made in the text. But I think that $\neg p$, so John must be wrong.' This is obviously objectionable.

In fact, our extension of Mid-Term is an instance of dogmatic reasoning that Christensen himself seems to think is the height of irrational dogmatism. Recall that he concludes his discussion of this by writing 'Used as a general tactic, it [replying dogmatically] would seem to allow a non-expert to dismiss even the disagreement of large numbers of those he took to be experts in the field' (ibid). ${ }^{12}$ Christensen, then, thinks it's highly objectionable to be dogmatic in the face of one's (recognized) epistemic superiors. Moreover, the fact that Independence can explain what's wrong with this type of response is supposed to independently motivate Independence. Indeed, it's the only debate-neutral motivation Christensen provides for Independence. Unfortunately, Independence is false, and the weakest principle that still yields conciliationism that isn't uncontroversially false - Peer Independence - doesn't explain what's objectionable about dogmatic responses in the face of one's epistemic superiors. Thus, Peer Independence lacks the independent motivation that Independence has. ${ }^{13}$

Here is what I take the dialectic to look like now. The principle - Independence - that is supposed to be the focal point between conciliationists and anti-conciliationists, is not immune to counterexamples. Fortunately for conciliationists, claims that the debate turns on Independence are hyperbolic. There are two weaker principles that, if accepted, lead to conciliationism. The stronger of the two - SE Independence - is also not immune to counterexamples. This leaves just Peer Independence. Peer Independence is not open to uncontroversial counterexamples. However, it also lacks the independent motivation that

\footnotetext{
${ }^{12}$ For similar sentiments, see (Cohen, 2013, pg. 100) and Lackey (2008).

${ }^{13}$ Of course, there is another principle that builds in something about epistemic superiors. In order to yield conciliationism, the principle will have to say something like 'In evaluating the epistemic credentials of an epistemic peer's or epistemic superior's expressed belief that $p$...' This will explain what's wrong with our extension of Mid-Term because it will explain what's wrong with being dogmatic towards one's epistemic superiors. However, it won't explain what's wrong with being dogmatic with one's epistemic inferiors. Since this seems possible, this disjunctive principle still can't explain all instances of objectionably dogmatic reasoning. Thanks to Lisa Mirrachi for pointing all of this out.
} 
Independence has. Thus, results are mixed for the conciliationist. While she's lost a battle (or two), she hasn't lost the war.

\section{The War, Lost}

So far I've been careful not to appeal to any claims that are controversial in the dialectic between the conciliationist and the anti-conciliationist. I've only appealed to claims that both sides can agree to, at least qua conciliationist or anti-conciliationist. I will now throw this caution to the wind. I now will argue that Peer Independence is false. Surely the conciliationist will take offense. So much the worse for her.

Here's one counterexample to Peer Independence:

\section{Roommate}

You have a roommate, let's call him Mark, living with you at 10 Maple St. You and Mark have all the same evidence about whether Adams lives at 10 Maple St. You both were present when the realtor gave you a tour of the place, you both signed the same lease, you both moved in at the same time and have had the same types of perceptual experiences about the contents of the apartment, and you both know that Adams routinely gets mail sent to that address. Moreover, you both rationally think of the other person that they are just as likely as you are at arriving at a reasonable view about whether someone lives at a particular location. Despite the fact that Adams routinely gets mail at that address, you believe that Adams doesn't live there. Mark, however, does think Adams lives there.

First things first, it seems undeniable that you are permitted - required, even - to take a dim view of Mark's belief. Thus, you aren't required to conciliate in this case. I take it that conciliationists will agree. The important question is why is it that you are permitted to take a dim view of his belief.

Here's my answer. You can point to all of the excellent evidence you have that Adams no longer lives there. For example, the fact that you've examined the house thoroughly and haven't found any sign of Adams. You've also been told by the owner of the property that you are the only two people who have access to the apartment. You can discount the importance of the disagreement because Mark must be irrationally discounting the weight of this evidence. It seems fine for you to think that he is overwhelmingly likely to be wrong given the evidence you have. You presumably are happy to concede that the fact that Adams' mail is routinely delivered to your address is a reason to believe she lives there. But it seems fine for you to point out the fact that that evidence is massively outweighed. 
The catch, of course, is that this type of evaluation of the credentials of Mark's belief wouldn't be permissible if Peer Independence were true. You'd have to set aside your impeccable sensitivity to the evidence while evaluating the credentials of Mark's belief. This doesn't mean, as I suspect a conciliationist would quickly point out, that you are forced to conciliate. For it might be that there are reasons independent of your initial reasoning that justify taking a dim view of Mark's belief.

It's worth considering a conciliationist reply to this case. The story she would most likely appeal to is analogous to Christensen's response we considered in $\$ 2$. She might say that you can take a dim view of Mark's belief because (1) something must be going wrong with one of you and (2) you can rule out that something is going wrong with you. If it's reasonable to think these two things, then you can conclude that something is going wrong with Mark. And if it's reasonable to think this, then you don't have to take his view seriously.

My reply to this story is the same as it was in $\$ 2$. It's not enough for the conciliationist to tell some story about some other reasons you have to discount the significance of Mark's belief. It might very well be that you have those reasons, but they are unnecessary. Think of it this way: It seems like you already have enough reason to discount Mark's view. You don't need to go investigate whether Mark is high or drunk (or if you are) in order to discount Mark's belief. Furthermore, it seems like you could find out that Mark is in his right mind and he still thinks Adams lives there. Intuitively, this doesn't matter. You already have sufficient reason to take a dim view of his belief. This isn't changed when you find out he's in his right mind. Since Peer Independence rules this out, it's reasonable to conclude that Peer Independence is false.

If Peer Independence is false, then we're at the end of the road. Peer Independence was the conciliationist's last hope for deriving conciliationism from a principle akin to Independence. Not only does it turn out that Peer Independence isn't independently motivated, it turns out that Peer Independence is false. Such was the life of the move from Independence to conciliationism.

\section{Appreciating the Scope of the Conclusion}

It is important to be clear about how far this goes. It doesn't show that conciliationism is false. Far from it. What it shows is that conciliationism cannot be derived from some independence principle.

This turns out to be dialectically important, I think, because the conciliationist replies to cases like Roommate found in Christensen (2007) and Elga (2007) are much more plausible than any explanation we've seen so far. The rub, though, is that it is implausible that these explanations are compatible with some type of independence principle. This is so despite Christensen and Elga's insistence upon Independence. Let me explain.

In Christensen (2007), Christensen argues that in the split-the-check example, you 
can discount your friend's belief because you have evidence that you used a highly reliable method and he didn't. This is because you know you used 'common-sense checking.' The fact that your friend's answer is so wildly off the mark is evidence that he did not use common-sense checking.

The problem with this in this context is that it is hard for me to see how you could know you used common-sense checking without appealing to your original reasoning. ${ }^{14}$ After all, the common-sense checking is part of your original reasoning. By appealing to that you are appealing to your original reasoning. So it doesn't seem like the most plausible version of this response is compatible with Independence.

Now consider Elga (2007)'s reply to these cases. He thinks that the correct conciliationist view allows you to take into account facts you've learned about the conditions of disagreement after you become aware of the disagreement. And in cases like the split-thecheck case and Roommate, he claims you come to know that your friend is crazy. It is because of this that you don't have to take his view seriously - in effect, you demote him from epistemic peerhood.

I agree that the fact that your friend is crazy is sufficient reason to discount his belief. But, again, the most plausible explanation of why you know this appeals to your original reasoning. This is because it's plausible that you are in a position to know your friend is crazy as soon as you find out about the disagreement. But surely at that point the best evidence you have that he's crazy are the reasons and reasoning that led you to your original conclusion. You needn't have any extra evidence about his state of mind; fortunately, you don't need any extra evidence. The reasons and reasoning that you used initially sufficiently support thinking he is crazy.

Compare this with the response from Christensen (2011) we considered before. According to that response, in order to discount your peer's belief, you have to do some extra reasoning. Namely, you have to reason to the conclusion that your friend is crazy or much less likely to be right than you from premises having to do with the likelihood that something is amiss with your friend rather than you. On that line, you have to consider whether it's more likely you actually double checked/are sane/are sober than it is that your peer actually double checked/is sane/is sober. As we've already seen, this extra bit of reasoning seems superfluous. It seems like you're already in a position to permissibly discount your friend's belief.

What this shows is that while it is true that one reason why you can discount your friend's belief is that he's crazy, the most plausible explanation for why this is appeals to your original reasons and reasoning. You are in a position to know your friend is crazy because of your original reasons and reasoning.

At this point it might not be clear what exactly my view is about the reason why the characters in our examples can discount the beliefs of those they disagree with. Above I

\footnotetext{
${ }^{14}$ For a similar argument for this conclusion, see Bogardus (2009).
} 
said that the initial reasons and reasoning were enough, but in this section I am agreeing with Christensen and Elga that it is okay to discount your friend's belief by appealing to the fact that he's crazy.

On my view, the primary reasons you can discount your friend's belief are the reasons that you initially relied on. You can justify why you discount your friend's belief by pointing to the reasons that initially led you to your belief. However, the quality of those reasons/reasoning also puts you in a position to know that your friend is crazy. Moreover, part of your reasoning involved common-sense checking. Thus, your original reasoning puts you a position to cite some additional reasons for discounting your friend's belief. You may cite these if you wish; they may even be sufficient justification for discounting your friend's belief. But they are optional. Your original reasons suffice. ${ }^{15}$

The upshot here is that while my conclusions don't threaten conciliationism per se, the most plausible conciliationist responses to the types of cases we've been considering are incompatible with independence principles. Again, so much the worse for independence principles.

\section{Conclusion}

Conciliationists about disagreement should stop trying to derive their view from independence principles. This is because they are false. I've shown that the most demanding independence principle - Independence - is false. The weaker principles - SE Independence and Peer Independence - aren't as obviously false. However, it is still very plausible that they are. Moreover, they are not independently motivated by what extant conciliationists have used to motivate Independence. Thus, at the very least, conciliationists have to motivate the weaker principles.

As the rest of the paper shows, this is not the best strategy for the conciliationist to pursue. We should all conclude that conciliationism cannot be derived from an independence principle. What the conciliationist should do, then, is develop a well motivated explanation of when one's original reasons are strong enough to ground a permission to dismiss the opinion of someone who was - at least pre-disagreement - considered a peer. This conciliationism, if it exists, would have significant advantages over extant conciliationist theories. Whether such a view exists is a question for another occasion.

\footnotetext{
${ }^{15}$ This might allow for something like a test for the conciliationist to determine whether one's original reasons are strong enough to ground a permission to dismiss: Do you they put you in a position to think your peer is crazy or otherwise epistemically suspect? I won't consider the merits of this test; I'll leave that to conciliationists.
} 


\section{References}

Bogardus, T. (2009). A vindication of the equal weight view. Episteme. [cited on pg. 12]

Christensen, D. (2007). Epistemology of disagreement: The good news. The Philosophical Review. [cited on pg. 11]

Christensen, D. (2009). Disagreement as evidence: The epistemology of controversy. Philosophy Compass, 4(5). [cited on pg. 2]

Christensen, D. (2011). Disagreement, question-begging, and epistemic self-criticism. Philosophers' Imprint, 11(6). [cited on pg. 2, 3, 5, 12]

Cohen, S. (2013). A defense of the (almost) equal weight view. In J. Lackey \& D. Christensen (Eds.), The Epistemology of Disagreement: New Essays. Oxford University Press. [cited on pg. 2, 9]

Copp, D. (2007). Morality in a Natural World: Selected Essays in Metaethics. Cambridge University Press. [cited on pg. 3]

Elga, A. (2007). Reflection and disagreement. Noûs. [cited on pg. 2, 11, 12]

Fitelson, B. \& Jehle, D. (2009). What is the 'equal weight view'? Episteme. [cited on pg. 2]

Hanin, M. (2012). Naturalistic moral realism and moral disagreement: David copp's account. Res Publica. [cited on pg. 3]

Kelly, T. (2008). Common sense as evidence: Against revisionary ontology and skepticism. Midwest Studies in Philosophy. [cited on pg. 2, 4]

Kelly, T. (2013). Disagreement and the burdens of judgement. In D. Christensen \& J. Lackey (Eds.), The Epistemology of Disagreement: New Essays. Oxford University Press. [cited on pg. 2, 4]

King, N. L. (2012). Disagreement: The skeptical arguments from peerhood and symmetry. In D. E. Machuca (Ed.), Disagreement and Skepticism. Routledge. [cited on pg. 2]

Kornblith, H. (2010). Belief in the face of controversy. In R. Feldman \& F. Warfield (Eds.), Disagreement. Oxford University Press. [cited on pg. 2]

Lackey, J. (2008). What should we do when we disagree? In T. S. Gendler \& J. Hawthorne (Eds.), Oxford Studies in Epistemology. Oxford University Press. [cited on pg. 2, 9] 
Lackey, J. (2010). A justificationist view of disagreement's epistemic significance. In A. M. Adrian Haddock \& D. Pritchard (Eds.), Social Epistemology. Oxford University Press. [cited on pg. 4]

Sorensen, R. (1988). Dogmatism, junk knowledge, and conditionals. The Philosophical Quarterly. [cited on pg. 4]

Sosa, E. (2013). The epistemology of disagreement. In J. Lackey \& D. Christensen (Eds.), The Epistemology of Disagreement: New Essays. Oxford University Press. [cited on pg. 2, 4]

Street, S. (2011). Mind-independence without the mystery: Why quasi-realists can't have it both ways. In R. Shafer-Landau (Ed.), Oxford Studies in Metaethics. Oxford University Press. [cited on pg. 3]

Vavova, K. (FC). Debunking evolutionary debunking. In R. Shafer-Landau (Ed.), Oxford Studies in Metaethics. Oxford University Press. [cited on pg. 3] 